\title{
Adsorption of Remazol Brilliant Violet 5R (RBV-5R) and Remazol Brilliant Blue R (RBBR) from Aqueous Solution by Using Agriculture Waste
}

\author{
Hong Jian Lai \\ Department of Civil and Construction Engineering, Faculty of Engineering and Science, Curtin University Malaysia, CDT \\ 250, Miri, Malaysia \\ Correspondence: 700014427@student.curtin.edu.my
}

SUBMITTED: 29 May 2021; REVISED: 15 June 2021; ACCEPTED: 17 June 2021

\begin{abstract}
The ability of agricultural waste materials to remove synthetic dyes such as Remazol Brilliant Violet 5R (RBV-5R) and Remazol Brilliant Blue R (RBBR) from aqueous solutions was investigated. Dyes are a major source of water contamination that not only cause significant damage to water bodies but also have a negative effect on human health due to their high toxicity and carcinogenic nature. Agricultural wastes are renewable adsorbents because they are readily available and inexpensive, and they can also be used instead of conventional activated carbon. As a result, the removal of RBV-5R and RBBR from dye solutions by adsorption onto treated adsorbent was investigated in this review. The two best adsorbents out of ten were selected via a screening process with RBBR as the test dye. The key adsorbents in this analysis were coconut shells and mango seeds, which had the highest removal rate as compared to others. The experiment was continued with the chosen adsorbent to see how different initial dye concentrations, adsorbent dosage, contact time, $\mathrm{pH}$, and particle size affected dye adsorption. The results show that different parameters have different effects on the removal rate and adsorption potential of the adsorbent. The adsorption of dye from aqueous solution onto adsorbent was investigated using Fourier transform infrared spectroscopy (FTIR) to investigate the functional groups of the adsorbent before and after the adsorption operation, and it was discovered that the functional group affected the effectiveness or removal rate as well as the adsorption capability of adsorbents. According to the findings, 5 gram mango seeds can extract 85.54 percent of RBV-5R with adsorption power of $1.26 \mathrm{mg} / \mathrm{g}$. For 21 hours, coconut shells removed 74.39 percent of RBBR with an adsorption capacity of $8.01 \mathrm{mg} / \mathrm{g}$. The findings indicated that these agricultural wastes could be useful as an alternative adsorbent for removing dye from aqueous solutions.
\end{abstract}

Keyword: Agricultural waste; Synthetic dyes; Adsorption; Dye water.

\section{Introduction}

Water, human being requires a percentage of $60 \%$ of water content in a human's body. Thus, it is a major demand for all living organisms including us. Through research, humans are able 
to last without food for weeks, but they will last for a few days without water. With water shortage, all living organisms including humans probably dead. As a consequence, effluent discharge of dye to the river caused severe pollutants that affects the environment and civilians. In this era of globalization, the water around Malaysia has been polluted and getting more serious due to the increase in the textile industry. Water pollution is a massive issue in Malaysia which is caused mainly by industries. A good example is the textile industry. The reason behind this is that the huge amount of effluent discharge of dyes from the textile industry [1-5].

Dye wastewater or dye effluents contain hazardous chemicals. These chemicals are known as natural or synthetic dye do not dissolve easily due to their complex organic molecules, therefore it affects the ecosystem such as the quality of the water and the lives of living beings such as humans, animals, and trees. For example, the dyes produced from textile industries had a huge impact which triggers damaging the water bodies on the river [6,7] ,also preventing the sunlight from penetrating the river. Thus, aquatics living beings will be endangered due to the reduction in the rate of photosynthesis. Besides, this may affect the human nervous system dysfunction when humans took infected kinds of seafood. Therefore, dye wastewater should strictly be prevented. As technology advance, few multiple methods or techniques have been discovered physical, biological, and chemical in order to remove the dye molecules. Most methods such as biodegradation, ion exchange chemical oxidation, ozonation, reverse osmosis, electrochemical methods, or coagulation-flocculation have a high failure rate due to various reasons like difficulty to implement, costly, environmentally friendly, and required land area. On the other hand, less costly and have a high efficiency in dye effluent treatment which is the adsorption method is the perfect choice for this experiment [9].

One method of removing dye molecules from wastewater is by a process called the Absorption Process. This process uses activated carbon, or also known as activated charcoal, as an absorbent that can successfully remove many different types of dye molecules. However, this substance has been proven by many experiments to be pricey and to be a non-renewable factor that might soon be obsoleted. Research has already begun to look for a replacement for carbon. There are suggestions of which agricultural waste or by-products are proposed to be a substitute for activated carbon as these new methods are not only more affordable but as well as a more effective substance in removing the dye [14]. After a few kinds of research, there are many types of used agricultural waste and each of them has a different percentage of effectiveness to removes the dye. The researcher still seeking every type of agricultural wastes that has the most effective to remove the dye. Thus, the reason for using agricultural waste is because it is more eco-friendly to reuse waste objects.

\section{Materials and Methods}

\subsection{Dye solution and adsorbent}

Remazol Brilliant Violet 5R (RBV-5R) and Remazol Brilliant Blue R (RBBR) were obtained from Sigma- Aldrich with high laboratory grade. The physicochemical characteristics of the dye are shown in Table 1. The stock solution was made by dissolving $1 \mathrm{~g}$ of dye in 1 liter of distilled water. The series of $100,200,400,600$, and $800 \mathrm{mg} / \mathrm{L}$ of dye concentration was provided from this main dye solution. The stink bean was collected from a local market and cleaned by tap water to remove the dirt. The adsorbent was ground and dried in the oven at $105^{\circ} \mathrm{C}$ 
for 24 hours and sieved through $600 \mu \mathrm{m}$ sieve to obtain a similar average size of the adsorbent powder and stored it in an airtight container at room temperature.

\subsection{FTIR}

Fourier Transform Infrared Spectroscopy (FTIR) (Agilent Model: Cary 630) analysis was performed to determine the surface functional groups of adsorbents. It was recorded in the spectral range varied from $650 \mathrm{~cm}^{-1}$ to $4000 \mathrm{~cm}^{-1}$.

\subsection{Equilibrium study}

A UV-Vis spectroscopy was used to investigate the treated solutions' adsorption capacity and color removal percentage for each sample. Calculation conducted by using the equation shown below:

Colour removal $(\%)=\frac{C_{i}-C_{f}}{C_{i}} \times 100$

Adsorption capacity $(\mathrm{mg} / \mathrm{g})=\frac{C_{i}-C_{f}}{M} x V$

where $\mathrm{Ci}$ is the initial concentration of dye solution $(\mathrm{mg} / \mathrm{L}), \mathrm{Cf}$ is the final concentration of dye solution after adsorption $(\mathrm{mg} / \mathrm{L}), \mathrm{M}$ is the mass of adsorbent $(\mathrm{gm})$, and $\mathrm{V}$ is the volume of dye solution (L).

Table 1. Physical and chemical characteristics of RBBR and RBV5R.

\begin{tabular}{lll}
\hline \multicolumn{1}{c}{ Dye } & RBBR & \\
\hline Chemical \\
structure
\end{tabular}

The most effective two adsorbents used for the isotherm study are the Langmuir isotherm and Freundlich isotherm. Langmuir isotherm determines the contrast and quantifies the adsorption ability of the adsorbents also Langmuir isotherm describes the adsorption in the gas-solid phase. By balancing the dynamic equilibrium and adsorption relative rates it is able to consider the surface coverage. Freundlich isotherm is commonly applicable and it has consistently correlation coefficients to the adsorption process that conduct effectively on heterogonous surface and multilayers with non-uniform adsorption heat distributions. The adsorption 
intensity has a slope between 0 to 1 , as the value is closer to 0 it means that it is more heterogeneous. The equation below shown the Freundlich isotherm equation.

Langmuir equation: $\frac{\mathrm{C}_{\mathrm{e}}}{\mathrm{q}_{\mathrm{e}}}=\frac{1}{\mathrm{q}_{\mathrm{m}} \mathrm{K}_{\mathrm{L}}}+\frac{\mathrm{C}_{\mathrm{e}}}{\mathrm{q}_{\mathrm{m}}}$

Freundlich $\quad: \log q_{e}=\log K_{F}+\frac{1}{n \log C_{e}}$

where $\mathrm{Ce}$ is the concentration of adsorbate at equilibrium $(\mathrm{mg} / \mathrm{g})$, qe is the amount of adsorbate at equilibrium $(\mathrm{mg} / \mathrm{g})$, qm is equal to qe and $\mathrm{KL}$ is Langmuir constant related to adsorption capacity $(\mathrm{L} / \mathrm{mg}), \mathrm{KF}$ is adsorption capacity $(\mathrm{mg} / \mathrm{g})$, and $1 / \mathrm{n}$ is adsorption intensity.

For this research, the two models that are used which are pseudo-first-order and pseudosecond-order are used to analyze the adsorption process.

Pseudo-first-order rate law $: \ln \left[q_{e}-q(t)\right]=\ln q_{e}-k_{1} t$

Pseudo-second-order rate law: $\frac{\mathrm{t}}{\mathrm{q}(\mathrm{t})}=\frac{\mathrm{t}}{\mathrm{q}_{\mathrm{e}}}+\frac{1}{\mathrm{k}_{2} \mathrm{q}_{\mathrm{e}}^{2}}$

where qe is adsorption capacity at equilibrium time $(\mathrm{mg} / \mathrm{g}), \mathrm{q}(\mathrm{t})$ is the amount of adsorbate adsorbed at contact time $\mathrm{t}(\mathrm{mg} / \mathrm{g}), \mathrm{k}_{1}$ is the pseudo-first-order rate constant $\left(\mathrm{min}^{-1}\right)$, and $\mathrm{t}$ is contact time with the adsorbent ( $\mathrm{min})$, and $\mathrm{k}_{2}$ is the pseudo-second-order rate constant $(\mathrm{g} / \mathrm{mg}$ $\min )$ ).

\section{Results and Discussion}

\subsection{Screening of adsorbent}

The most two effective adsorbents that have the highest removal percentage, Remazol Brilliant Blue R (RBBR) was used as the testing dyes in the screening process. The adsorbents that are being used are banana peels, coconut shells, mango seeds, lemon peels, orange peels, pineapple peels, watermelon peels, papaya peels, and longan peels. For the recipe, a total of $50 \mathrm{ppm}$ concentration of dye solution is mixed with 0.5 grams of a several adsorbent into a conical flask respectively and then placed into an orbital shaker with $120 \mathrm{rpm}$ for 4 hours in an average of 30-degree Celsius temperature. Based on the results displayed in Figure 1, the two best adsorbents were coconut shells and mango seeds, both of with having a removal rate of $61.91 \%$ and $53.81 \%$ respectively. Despite longan peels adsorbent has a removal rate of as high as $44.58 \%$, it is still lower compared to the coconut shells and mango seeds. And among the eight adsorbents, the adsorbent that has the lowest removal rate is the lemon peels at $10.58 \%$, and the remaining adsorbent having a removal rate of lesser than $50 \%$. Even in the category of adsorption capacity, coconut shells and mango seeds have the highest adsorption capacity of $6.77 \mathrm{mg} / \mathrm{g}$ and $5.58 \mathrm{mg} / \mathrm{g}$. Lemon peels once again are the lowest in adsorption capacity at 1.18 $\mathrm{mg} / \mathrm{g}$ while the rest having a measurement of lower than $5 \mathrm{mg} / \mathrm{g}$. 


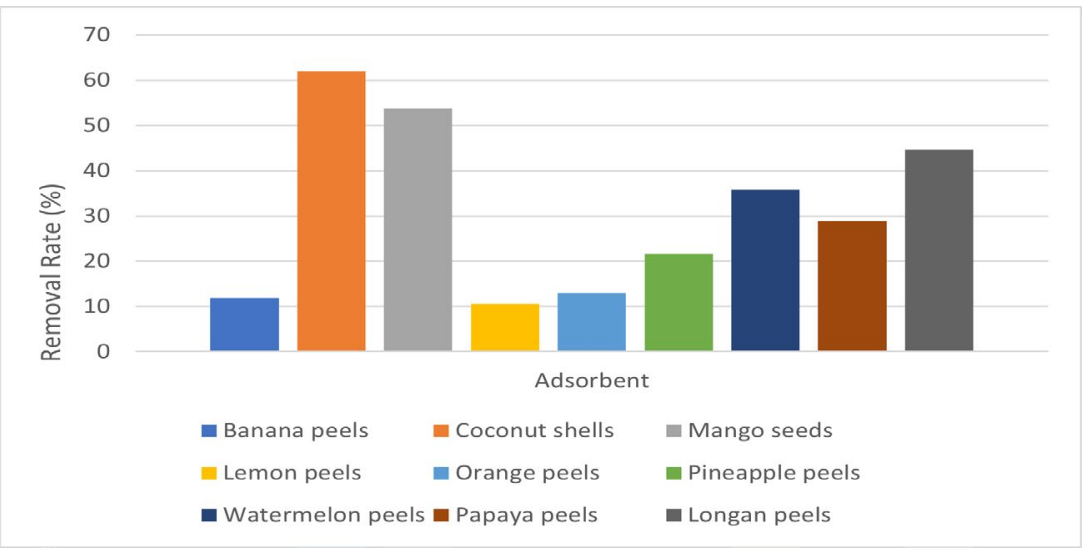

Figure 1. Graph of removal rate for a different type of adsorbents

\subsection{Batch studies}

According to the results shown in Figure 2, it can be concluded that the dye removal rate of the two adsorbents decreases with the increase of the initial dye concentration. The RBBR concentration increased from $10 \mathrm{ppm}$ to $150 \mathrm{ppm}$, and the removal rate of coconut shells in RBV-5R is decreased from $75.59 \%$ to $61.33 \%$ and RBBR are from $65.15 \%$ to $53.22 \%$, respectively. When the initial concentration of RBV-5R and RBBR increased from $10 \mathrm{ppm}$ to $150 \mathrm{ppm}$, the removal rate of mango seeds decreased from $88.31 \%$ to $71.07 \%$, and from $63.21 \%$ to $47.39 \%$. The amount of carbon adsorption per unit mass (qt) increases.

The above phenomenon can be explained by the active sites on the surface of the adsorbent. At low concentrations, the number of unoccupied active sites is large, which proved that the ratio of surface-active sites to the total number of dye molecules in the solution is large. When the molecules or ions of the dye interact with the adsorbent, these molecules, therefore, occupy the action centers on the carbon surface and can be removed from the solution. However, as the dye concentration increases, the active sites of the adsorbent are saturated and insufficient to absorb the dye molecules, so the removal percentage decreases $[16,17]$.
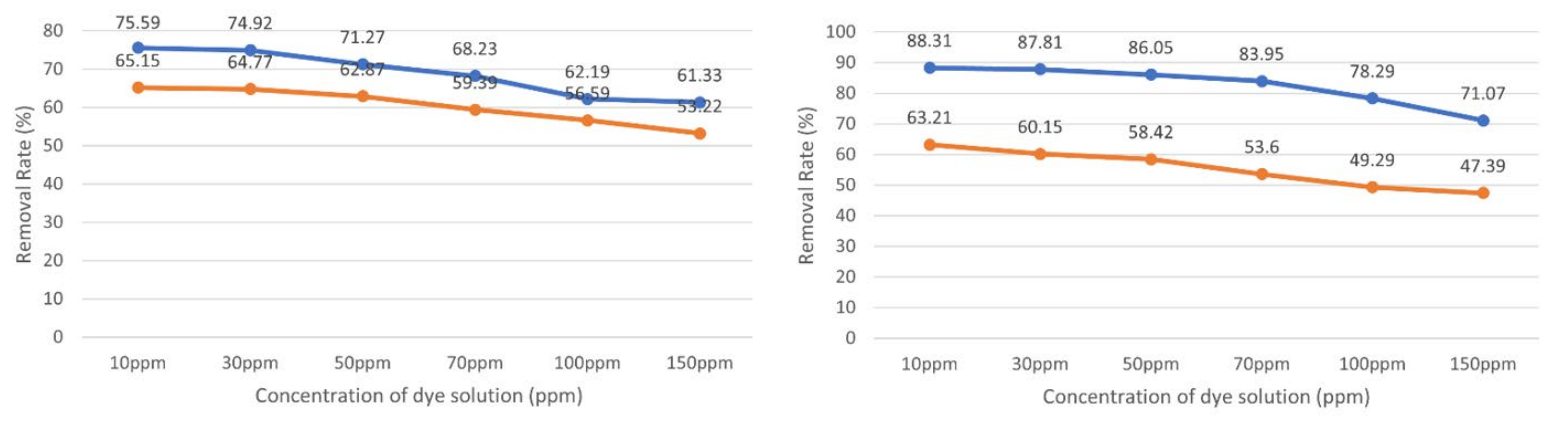

Figure 2. Effect of dye concentration RBBR and RBV-5R removal by coconut shells (left) and mango seeds (right).

Figure 3 shown that the rate of RBV-5R and RBBR removal increased linearly as the dosage of coconut shell was increased. For 0.5 gram of coconut shell, removal rate RBV-5R was 72.31 percent, and removal RBBR was 62.53 percent. Furthermore, removal RBV-5R was 78.58 percent and removal RBBR was 63.37 percent for 1 gram of coconut shell. Meanwhile, removal RBV-5R was 82.92 percent and removal RBBR was 68.72 percent for 3 gram of 
coconut shell. With that, the 5-gram process yielded the highest rate of coconut shell removal for both RBV-5R and RBBR which are 85.54 and 73.22 percent. As shown in Figure 3, raising the dosage of mango seeds from 0.5 gram to 5 gram increases the percentage of removal. Removal RBV-5R was 86.28 percent and removal RBBR was 56.29 percent for 0.5 gram of mango seeds. Furthermore, removal RBV-5R was 87.39 percent and removal RBBR was 59.59 percent for 1 gram of mango seeds. Meanwhile, removal RBV-5R was 89.16 percent for 3 gram of mango seeds and removal RBBR was 66.73 percent. Finally, 5 gram of mango seeds resulted in 88.26 percent RBV-5R removal and 73.98 percent RBBR removal with 5 gram of mango seeds. Therefore, the 5-gram process yielded the highest mango seeds removal rate for both RBV-5R and RBBR. Overall, the results show that as the adsorbent dose increased, the dye removal rate increased. This can be explained by the previous research on the impact of dye concentration, which was influenced by the number of active sites available. The total number of active sites of the adsorbent increased as the dosage of the adsorbent was increased, as did the availability of unique adsorbent surfaces. This increased the number of active sites available for the adsorption process $[10,17]$.
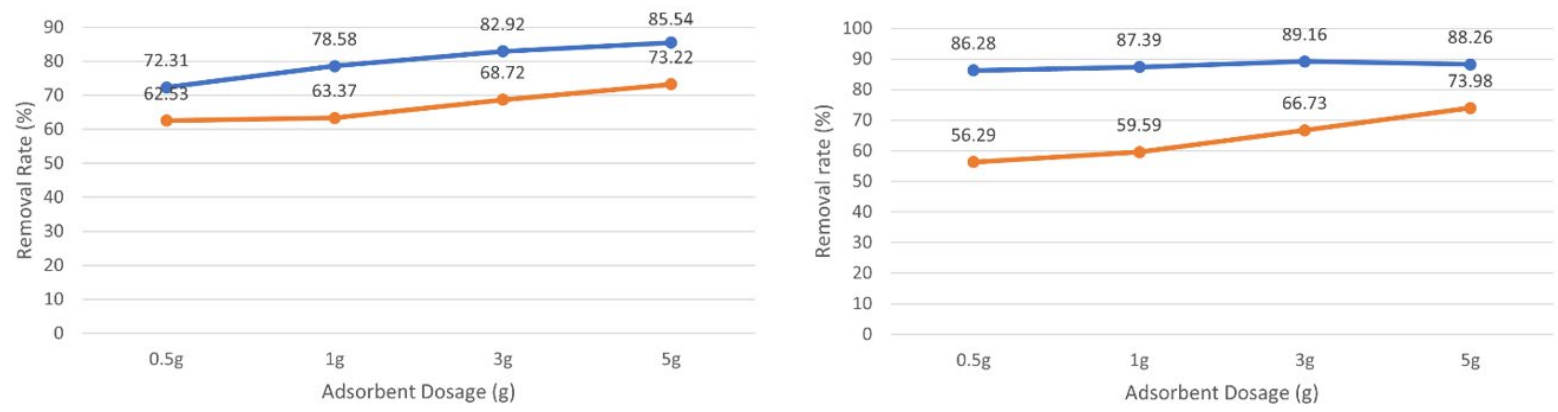

Figure 3. Effect of adsorbent dosage on RBBR and RBV-5R removal by coconut shells (left) and mango seeds (right).

Figure 4 shows the removal rate of Remazol Brilliant Violet 5R (RBV-5R) and Remazol Brilliant Blue R (RBBR) from coconut shells after 24 hours of contact time. Remazol Brilliant Violet 5R and Remazol Brilliant Blue $R$ clearance rates gradually increased in the first 18 and 21 hours, respectively, before significantly decreasing after that. As a consequence, the best times to remove PR and RBBR from coconut shells were 18 and 21 hours, respectively, with the highest removal rate when compared to other times. As seen in the graph above, the highest percentages of RBV-5R and RBBR elimination for coconut shells were 79.38 percent and 74.39 percent, respectively. With a 24-hour contact time in Figure 4, the mango seeds were removed by Remazol Brilliant Violet 5R (RBV5R) and Remazol Brilliant Blue R (RBBR). After the maximal peak, the elimination rate of RBV-5R and RBBR climbed gradually for the first 12 hours, then fell somewhat. As a result, the most effective period for mango seeds to remove RBV-5R and RBBR was 12 hours, with the highest removal rate compared to other durations. As demonstrated in the figure above, the highest percentages of RBV-5R and RBBR elimination for mango seeds were 77.28 percent and 69.7 percent, respectively. When all of the findings are compared, this can be stated that the coconut shells and mango seeds were the most effective adsorbents in removing RBV-5R, as RBV-5R removal rates for both adsorbents were greater than RBBR removal rates. Furthermore, the percentage of removal was shown to be higher at first but then decreased after a given amount of contact time. This is due to the fact that the attractive forces between the adsorbent and dye molecules were strong enough, and 
there was enough time for them to interact $[10,17]$. However, because equilibrium between the quantity of dye molecule adsorbed by the adsorbent and the quantity of dye molecule remaining in the solution was not attained, the removal rate decreased. As a result, the adsorbent's active site did not fully interact with the dye molecule, and as the adsorbent reached its limit, its ability to absorb the dye molecule was reduced as well. Because the amount of dye molecule adsorbed reduced the attractive force of functional groups on the adsorbent's surface and the dye molecule was not effective, the dye molecule was left in the solution [6,19]. The larger the collision between adsorbent and adsorbate particle, the longer the adsorption contact time.
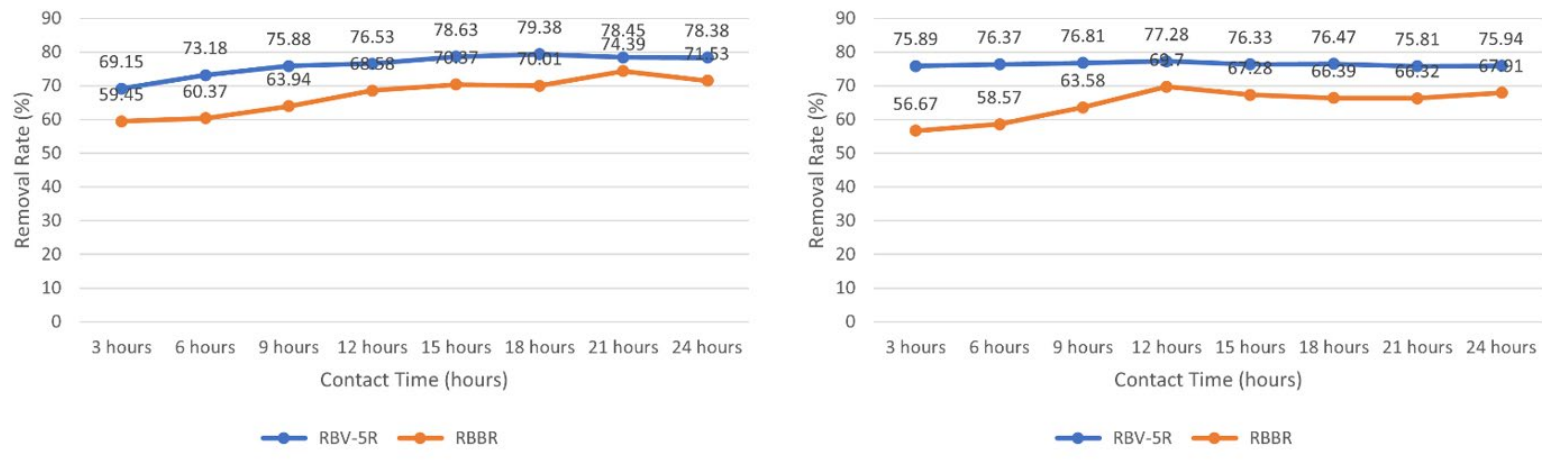

Figure 4. Effect of contact time on RBBR and RBV-5R removal by coconut shells (left) and mango seeds (right)

According to Figures 5, the acid medium had the highest removal rate of coconut shells in RBV-5R and RBBR, with scores of 65.49 percent and 59.68 percent, respectively. While acid and neutral medium had the highest removal rate of mango seeds in RBV-5R and RBBR, with scores of 69.96 percent and 60.31 percent, respectively. The term "neutral" refers to the absence of a positive or negative charge on the adsorbent's surface. The percentage of elimination dropped as the $\mathrm{pH}$ of the dye solution climbed until it reached alkalinity. Surface characteristics of the adsorbents and dissociation or ionization of the adsorbate molecules can explain this behavior. Low $\mathrm{pH}$ causes an increase in hydrogen $\left(\mathrm{H}^{+}\right)$ion concentration; as a result of adsorbing $\mathrm{H}+$ ions, the adsorbent will have a positive charge. Because the adsorbent surface is positively charged at low $\mathrm{pH}$, there is a large electrostatic attraction between the dye molecule and the positively charged adsorbent surface, resulting in increased adsorption. The negatively charged sites grew as the $\mathrm{pH}$ of the dye solution increased, while the positively charged sites dropped. Due to electrostatic repulsion, a negatively charged surface location on the adsorbent does not favor dye molecule adsorption [16]. As a result, the rate of adsorption removal in the alkaline medium decreases.
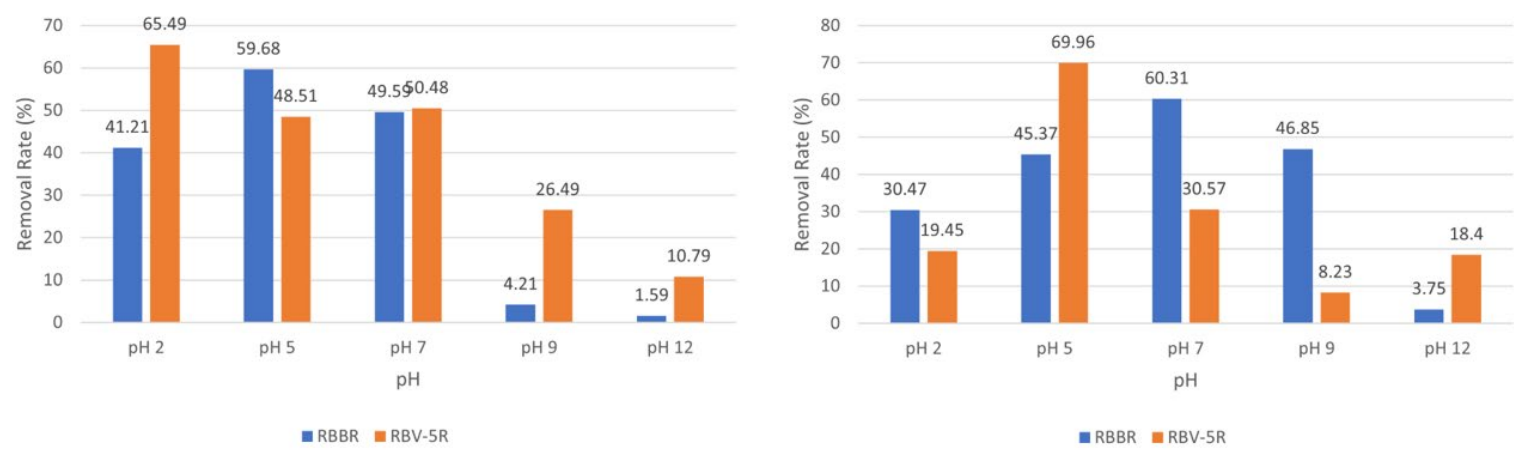

Figure 5. Effect of $\mathrm{pH}$ on RBBR and RBV-5R removal by coconut shells (left) and mango seeds (right). 
For both Remazol Brilliant Violet 5R (RBV-5R) and Remazol Brilliant Blue R (RBBR) dyes, the percentage of dye removal increased as the particle size of both adsorbents decreased from Figure 6 . The dye was removed more effectively with the $150 \mu \mathrm{m}$ adsorbent. The greater surface area for adsorption per unit mass, or larger surface retention, and greater accessibility to adsorbent pores, resulted in a higher adsorption potential with smaller adsorbent particles. Santhi et al. have published a similar finding [20].
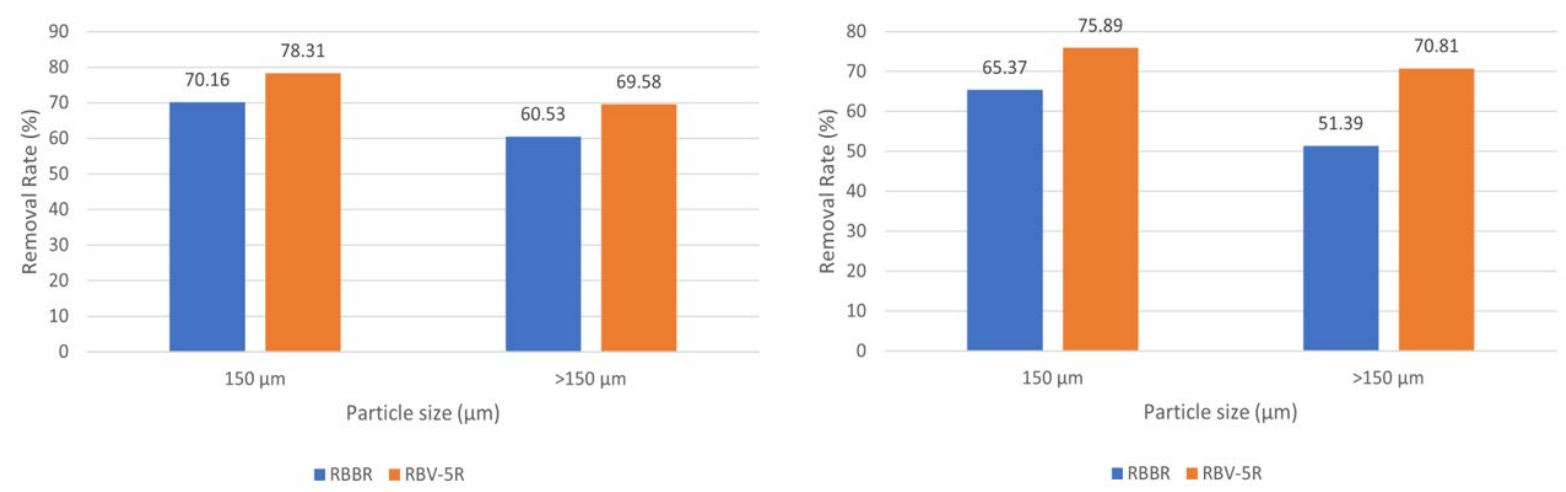

Figure 6. Effect of particle size on RBBR and RBV-5R removal rate by coconut shells (left) and mango seeds (right).

\subsection{FTIR}

The functional groups present in the raw adsorbent and adsorbent after the adsorption phase were identified using Fourier Transform Infrared Spectroscopy (FTIR) (Agilent Model: Cary 630 ) analysis in the $650-4000 \mathrm{~cm}^{-1}$ range. The adsorption potential can be affected by the chemical reactivity of functional groups on the adsorbent surface. The functional groups of different adsorbents vary, resulting in differences in adsorption capability. Figure 7F depicts the infrared spectrum of raw coconut shells with the peak at $3192.79 \mathrm{~cm}^{-1}$ caused by the hydroxyl functional group of alcohols with $\mathrm{O}-\mathrm{H}$ stretch. It indicates the presence of $\mathrm{CH}$ stretching at peak $2953.79 \mathrm{~cm}^{-1}$, which induces vibration of the $\mathrm{CH}, \mathrm{CH}_{2}$, and $\mathrm{CH}_{3}$ groups. However, at 1649.58, it shows the characteristic of $\mathrm{C}=\mathrm{C}$ bonds in aromatic rings. With peak $1018.79 \mathrm{~cm}^{-1}$, there was a variable strong bond, indicating that a group of silicates with Si-O stretch existed. Figures 7A and 7B showed the same functional group of alcohols at peaks $3357.35 \mathrm{~cm}^{-1}$ and $3342.51 \mathrm{~cm}^{-1}$, respectively. The vibrations of the N-H and $\mathrm{O}-\mathrm{H}$ functional groups are responsible for the large deviations of these peaks. The increments in the C-O carboxyl bands from $1650.51 \mathrm{~cm}-1$ to $1350.67 \mathrm{~cm}^{-1}$ and $1649.87 \mathrm{~cm}^{-1}$ to $1354.78 \mathrm{~cm}^{-1}$ for decolorization of RBV5R and RBBR, respectively, are another significant improvement. Changes in these band areas are usually caused by the behavior of carboxyl oxygen atoms. The peak at $991.75 \mathrm{~cm}^{-1}$ and $990.78 \mathrm{~cm}^{-1}$ indicates the presence of a silicate group, which can be attributed to Si-O bending and stretching, but it has become sharp due to the stretching of the carboxyl group beside it.

Based on Figure 7C, the first peak on the graph was $3195.13 \mathrm{~cm}^{-1}$ which it assigned to the stretching of $\mathrm{O}-\mathrm{H}$ vibrations which were the alcohol group. Thus, this is also probably obtained on the carboxylic acid which is $\mathrm{CO}-\mathrm{OH}$ functional group. It indicates the presence of $\mathrm{C}-\mathrm{H}$ stretching at peak $2861.61 \mathrm{~cm}^{-1}$ and $2719.79 \mathrm{~cm}^{-1}$, which induces vibration of the asymmetric $\mathrm{C}-\mathrm{H}$ and $\mathrm{C}-\mathrm{H}$ bands. In the wavenumber between $1400 \mathrm{~cm}^{-1}$ to $1300 \mathrm{~cm}^{-1}$ 
considered to the alkyl groups which are $\mathrm{C}-\mathrm{H}$ bending [14]. In the temperature between 600 to $1000{ }^{\circ} \mathrm{C}$, the intensity of the group bands decreases, respectively. Meanwhile, at the peak of $1678.71 \mathrm{~cm}^{-1}$ and $1337.12 \mathrm{~cm}^{-1}$ are the presents of $\mathrm{NH}$ and $\mathrm{C}=\mathrm{O}$ carboxylic acid vibration. Figures 27 and 28 showed the same functional group of $\mathrm{OH}$ vibrations at peaks $3271.86 \mathrm{~cm}^{-1}$ and $3274.71 \mathrm{~cm}^{-1}$, respectively. The vibrations of the $\mathrm{O}-\mathrm{H}$ functional groups are responsible for the large deviations of these peaks. The increments in the C-H bending from $2869.31 \mathrm{~cm}^{-1}$ to $2719.77 \mathrm{~cm}^{-1}$ and $2869.31 \mathrm{~cm}^{-1}$ to $2721.53 \mathrm{~cm}^{-1}$ for decolorization of RBV-5R and RBBR, respectively, are another significant improvement. The peak at $984.61 \mathrm{~cm}^{-1}$ and $991.65 \mathrm{~cm}^{-1}$ indicates the presence of a carboxylic acid group, which can be attributed to $\mathrm{C}=\mathrm{O}$ bending and stretching as seen in Figure 7D and Figure 7E.
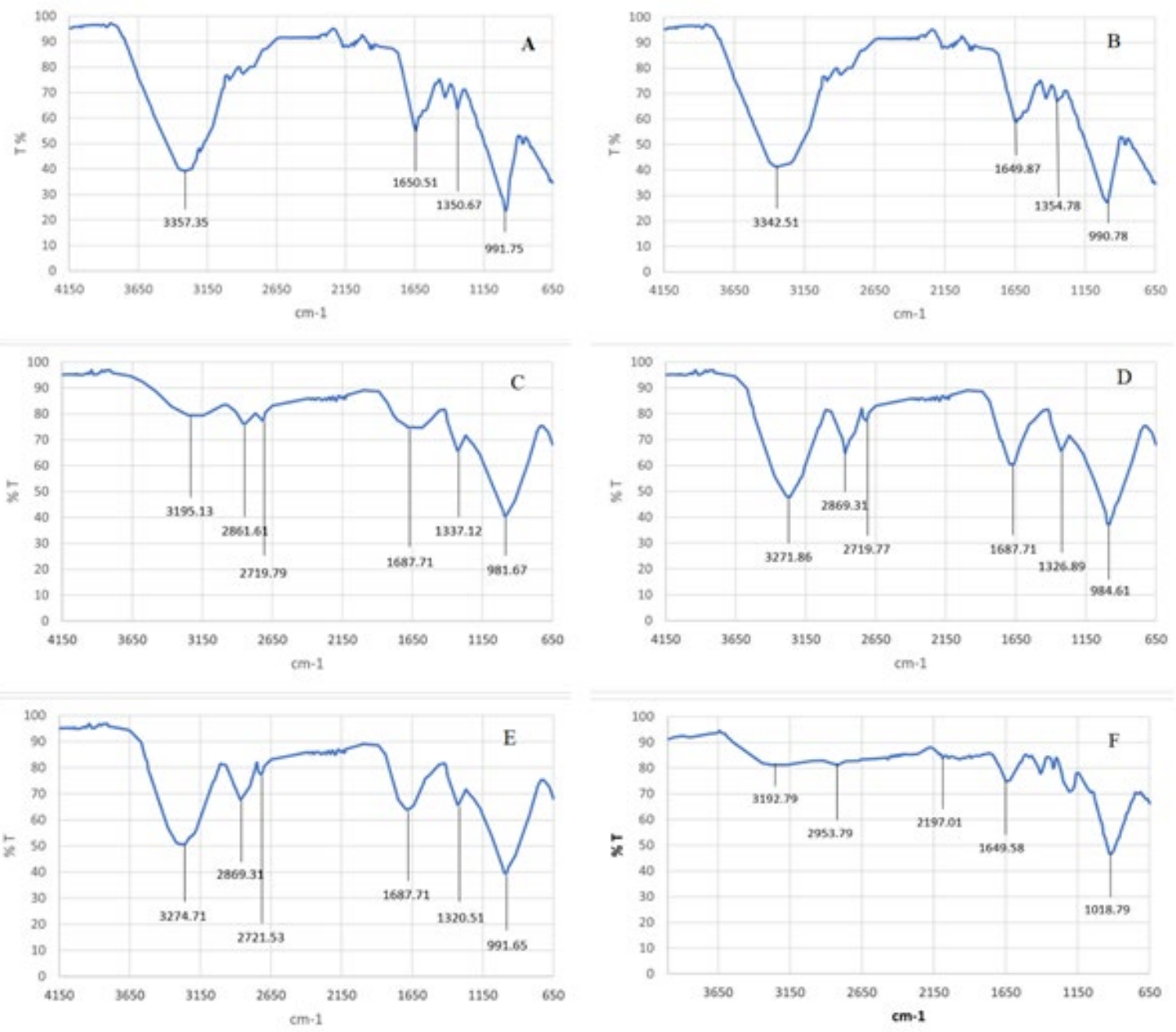

Figure 7. FTIR spectra of coconut shell after RBV-5R decolorization (A), after RBBR decolorization (B) raw (F); and mango seed: raw (C), after RBV-5R decolorization (D), after RBBR decolorization (E).

\subsection{Isotherm and kinetic studies}

The calculation of $\mathrm{R}_{\mathrm{L}}$ by using the Langmuir isotherm model specifies the adsorption process. The value $\mathrm{R}_{\mathrm{L}}$ is shown in Table 2 indicates that the coconut shells and mango seeds fall in the range of $0-1$. Therefore, the value of coefficient $\mathrm{R}^{2}$ is $(0.9318,0.7863,0.9034,0.96)$ specify that method used of Langmuir isotherm. The slope and intercept of both pseudo-first and second-order plots yield a linear relationship, from which the values of $\mathrm{k} 1, \mathrm{k} 2$, and Qe can be 
calculated. The second-order kinetic model has a higher correlation coefficient (0.9984 and 0.9978) than the first-order kinetic model (0.9796 and 0.9689). This confirmed that chemisorption, which involves the valence of forces through sharing or exchange of electrons, is the rate-limiting step [21]. Furthermore, the measured equilibrium adsorption potential (Qe) for the pseudo-first-order kinetic model $(1.4377 \mathrm{mg} / \mathrm{g}, 6.2592 \mathrm{mg} / \mathrm{g}, 1.9179 \mathrm{mg} / \mathrm{g}$, and 5.0139 $\mathrm{mg} / \mathrm{g}$ ) was substantially lower than the calculated value of Qe for the pseudo-second-order kinetic model $(9.3781 \mathrm{mg} / \mathrm{g}, 9.7831 \mathrm{mg} / \mathrm{g}, 8.5739 \mathrm{mg} / \mathrm{g}$, and $6.9138 \mathrm{mg} / \mathrm{g})$. As a result, it was assumed that the pseudo-second-order model provides a stronger correlation of adsorption fit for both adsorbents than the pseudo-first-order model, implying that the rate-limiting stage is chemisorption [22].

Table 2. Kinetic parameters for RBV5R and RBBR on agricultural waste

\begin{tabular}{|c|c|c|c|c|c|c|c|}
\hline \multirow[b]{2}{*}{ Dye } & \multirow[b]{2}{*}{ Kinetic model } & \multicolumn{3}{|c|}{ Coconut shells } & \multicolumn{3}{|c|}{ Mango seeds } \\
\hline & & $\begin{array}{c}k_{1} \text { or } k_{2} \\
\left(\min ^{-1}\right)\end{array}$ & $Q_{e}(m g / g)$ & $\mathbf{R}^{2}$ & $\begin{array}{c}k_{1} \text { or } k_{2} \\
\left(\mathrm{~min}^{-1}\right)\end{array}$ & $Q_{\mathrm{e}}(\mathrm{mg} / \mathrm{g})$ & $\mathbf{R}^{2}$ \\
\hline \multirow[t]{2}{*}{ RBV5R } & Pseudo $1^{\text {st }}$ order & -0.0018 & 1.4377 & 0.9868 & -0.0011 & 6.2592 & 0.9796 \\
\hline & Pseudo $2^{\text {nd }}$ order & 0.0073 & 9.3781 & 0.9981 & 1.7396 & 9.7831 & 0.9984 \\
\hline \multirow[t]{2}{*}{ RBBR } & Pseudo $1^{\text {st }}$ order & -0.0009 & 1.9179 & 0.9555 & -0.0005 & 5.0139 & 0.9689 \\
\hline & Pseudo $2^{\text {nd }}$ order & 0.0181 & 8.5739 & 0.9984 & 0.0178 & 6.9138 & 0.9978 \\
\hline
\end{tabular}

Langmuir and Freundlich isotherm models are used to determine the adsorption capacity and initial concentration of dye parameters which are RBV5R and RBBR on each of the adsorbent coconut shells and mango seeds. The figure and table above are the results obtained. The linear graph is plotted as $\mathrm{C}_{\mathrm{e}} / \mathrm{q}_{\mathrm{e}}$ versus $\mathrm{C}_{\mathrm{e}}$ in Figure 8. The figure shows the adsorption by using the method Langmuir isotherm model for each of the adsorbents. The calculation of $\mathrm{R}_{\mathrm{L}}$ by using the Langmuir isotherm model specifies the adsorption process.. Therefore, the value of coefficient $\mathrm{R}^{2}$ is $(0.9318,0.7863,0.9034,0.96)$ specify that method used of Langmuir isotherm. Moreover, the Freundlich isotherm model proves the $\mathrm{R}^{2}$ by referring to the adsorption data which are $(0.9868,0.9251,0.9924,0.987)$. The linear graph line of $\log \mathrm{q}_{\mathrm{e}}$ versus $\log \mathrm{C}_{\mathrm{e}}$ obtained a straight-line interception at the $\mathrm{y}$-axis be elected by the value of $\mathrm{K}_{\mathrm{F}}$ with slop $1 / \mathrm{n}$. The linear plot shows the adsorption by using the method Freundlich isotherm model for each of the adsorbents. When the $1 / \mathrm{n}$ value is near to 0 demonstrates that adsorption is heterogeneous, when the $1 / \mathrm{n}$ is below 1 specify a normal Freundlich isotherm, and $1 / \mathrm{n}$ is near between 0 to 1 is indicative of adsorption. Therefore, the values of $1 / \mathrm{n}(0.6871$, $0.4915,0.8581,0.7915)$ are between 0 to 1 , shows that the results are heterogeneous and favorable [23]. 

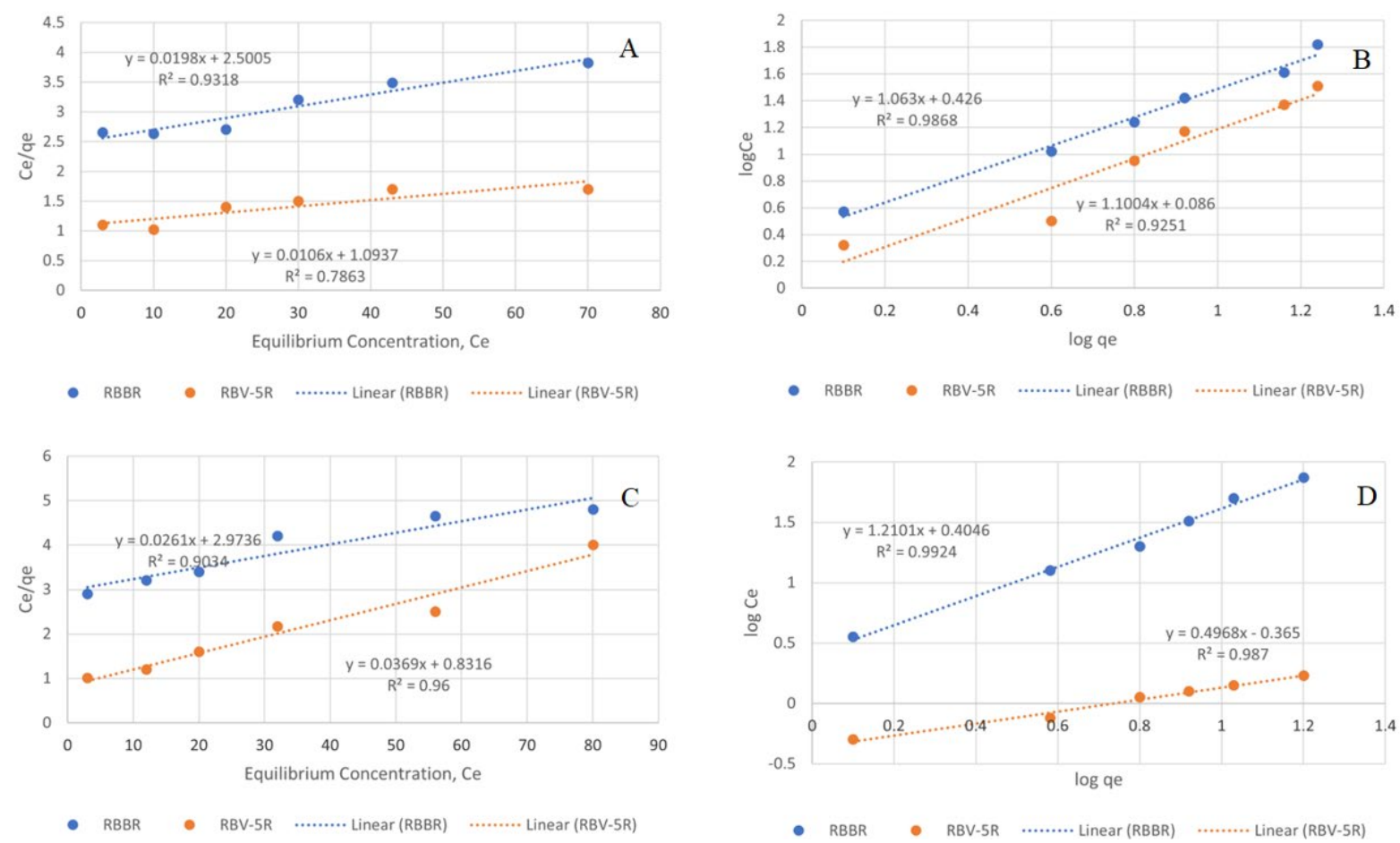

Figure 8. Isotherm model coconut shell: Langmuir (A), Freundlich (B); and mango seed: Langmuir (C), Freundlich (D).

\section{Conclusions}

To substitute activated carbon in the adsorption process, the most effective adsorbent for removing RBV-5R and RBBR was described in this study. Coconut shells and mango seeds, however, were the best two picked from screening with the dye RBV-5R, with removal percentages of 75.59 percent and 88.31 percent, respectively. The first part of the first task, which was to find the most powerful adsorbent for removing the RBV-5R and RBBR dyes, was successfully completed. The second part of the first goal was met when FTIR analysis was used to evaluate the functional groups present in the adsorbents. Different types of functional groups found in adsorbents can result in varying levels of dye solution removal capability. The analysis of two adsorption isotherms, Langmuir and Freundlich, revealed that the Freundlich isotherm had a better fitting model than the Langmuir isotherm, as well as a higher $\mathrm{R}^{2}$ for both adsorbent graphs. This proved that adsorption is heterogeneous and occurs as a result of physical-chemical interactions. The rate of adsorption, on the other hand, was discovered to follow a pseudo-second-order kinetics model with a high correlation coefficient. The third goal of this report, which was to investigate the adsorption isotherm and kinetic studies of the adsorption mechanism, was met successfully.

\section{Acknowledgements}

The authors thank Curtin University Malaysia for facilitating this work.

\section{Conflicts of Interest}

The authors declare no conflict of interest. 


\section{References}

[1] Hadibarata, T.; Kristanti, R.A.; Mahmoud, A.H. (2020). Occurrence of endocrine-disrupting chemicals (EDCs) in river water and sediment of the Mahakam River. Journal of Water and Health, 18, 38-47, https://doi.org/10.2166/wh.2019.100.

[2] Hadibarata, T.; Syafiuddin, A.; Ghfar, A.A. (2019). Abundance and distribution of polycyclic aromatic hydrocarbons (PAHs) in sediments of the Mahakam River. Marine Pollution Bulletin, 149, 110650. https://doi.org/10.1016/j.marpolbul.2019.110650.

[3] Yang, W.; Hadibarata, T.; Mahmoud, A.H.; Yuniarto, A. (2020). Biotransformation of pyrene in soil by microbes in the presence of earthworm Eisenia fetida. Environmental Technology and Innovation, 18, 100701. https://doi.org/10.1016/j.eti.2020.100701.

[4] Awa, S.H.; Hadibarata, T. (2020). Removal of Heavy Metals in Contaminated Soil by Phytoremediation Mechanism: a Review. Water, Air, \& Soil Pollution, 231, 46. https://doi.org/10.1007/s11270-020-4426-0.

[5] Katheresan, V.; Kansedo, J.; Lau, S.Y. (2018). Efficiency of various recent wastewater dye removal methods: A review. Journal of Environmental Chemical Engineering, 6, 4676-4697, https://doi.org/10.1016/j.jece.2018.06.060.

[6] Nazifa, T.H.; Habba, N.; Salmiati; Aris, A.; Hadibarata, T. (2018). Adsorption of Procion Red MX5B and Crystal Violet Dyes from Aqueous Solution onto Corncob Activated Carbon. Journal of the Chinese Chemical Society, 65, 259-270, https://doi.org/10.1002/jccs.201700242

[7] El-Aassar, M.R.; Fakhry, H.; Elzain, A.A.; Farouk, H.; Hafez, E.E. (2018). Rhizofiltration system consists of chitosan and natural Arundo donax L. for removal of basic red dye. International Journal of Biological Macromolecules, 120, 1508-1514, https://doi.org/10.1016/j.ijbiomac.2018.09.159.

[8] Carneiro, P.A.; Umbuzeiro, G.A.; Oliveira, D.P.; Zanoni, M.V.B. (2010). Assessment of water contamination caused by a mutagenic textile effluent/dyehouse effluent bearing disperse dyes. Journal of Hazardous Materials, 174, 694-699, https://doi.org/10.1016/j.jhazmat.2009.09.106.

[9] Lazim, Z.M.; Mazuin, E.; Hadibarata, T.; Yusop, Z. (2015). The Removal of Methylene Blue and Remazol Brilliant Blue R Dyes by Using Orange Peel and Spent Tea Leaves. Jurnal Teknologi, 74, 129-135. http://dx.doi.org/10.11113/jt.v74.4882.

[10] Rahmat, N.A.; Ali, A.A.; Salmiati; Hussain, N.; Muhamad, M.S.; Kristanti, R.A.; Hadibarata, T. (2016). Removal of Remazol Brilliant Blue R from Aqueous Solution by Adsorption Using Pineapple Leaf Powder and Lime Peel Powder. Water, Air, \& Soil Pollution, 227, 105, https://doi.org/10.1007/s11270-016-2807-1.

[11] Santana, C.S.; Nicodemos Ramos, M.D.; Vieira Velloso, C.C.; Aguiar, A. (2019). Kinetic Evaluation of Dye Decolorization by Fenton Processes in the Presence of 3-Hydroxyanthranilic Acid. Int J Environ Res Public Health, 16, 1602. https://doi.org/10.3390/ijerph16091602.

[12] Sharma, S.; Rashmitha, C.S.; Pandey, L.M. (2020). Synthesis and characterization of methyl acrylamide cellulose nanowhiskers for environmental applications. Letters in Applied NanoBioScience, 9, 2020, 880-884, https://doi.org/10.33263/LIANBS91.880884.

[13] Eftekhari, S.; Foroughifar, N.; Khajeh-Amiri, A.; Hallajian, S. (2020). Synthesis and characterization of polymeric nanocomposites based on poly-melamineparaformaldehyde and superparamagnetic silicon dioxide loaded Iron(III) oxide core-shell composite magnetic nanoparticles. Letters in Applied NanoBioScience, 9, 914-918, https://doi.org/10.33263/LIANBS91.914918.

[14] Rahmat, N.A.; Hadibarata, T.; Yuniarto, A.; Elshikh, M.S.; Syafiuddin, A. (2019). Isotherm and kinetics studies for the adsorption of bisphenol A from aqueous solution by activated carbon of Musa acuminata. IOP Conference Series: Materials Science and Engineering, 495, https://doi.org/10.1088/1757- 899x/495/1/012059.

[15] Ayawei, N.; Ebelegi, A.N.; Wankasi, D. (2017). Modelling and Interpretation of Adsorption Isotherms. Journal of Chemistry, 2017, 3039817. https://doi.org/10.1155/2017/3039817.

[16] Pathania, D.; Sharma, S.; Singh, P. (2017). Removal of methylene blue by adsorption onto activated carbon developed from Ficus carica bast. Arabian Journal of Chemistry, 10, S1445-S1451, https://doi.org/10.1016/j.arabjc.2013.04.021.

[17] Anuar, F.I.; Hadibarata, T.; Muryanto; Yuniarto, A.; Priyandoko, D.; Arum, S.A. (2019). 
Innovative chemically modified biosorbent for removal of procion red. International Journal of Technology, 10, 776-786, https://doi.org/10.14716/ijtech.v10i4.2398.

[18] Geçgel, Ü.; Özcan, G.; Gürpınar, G.Ç. (2013). Removal of Methylene Blue from Aqueous Solution by Activated Carbon Prepared from Pea Shells (Pisum sativum). Journal of Chemistry, 2013, 614083. https://doi.org/10.1155/2013/614083.

[19] Khori, N.K.E.M.; Hadibarata, T.; Elshikh, M.S.; Al-Ghamdi, A.A.; Salmiati; Yusop, Z. (2018). Triclosan removal by adsorption using activated carbon derived from waste biomass: Isotherms and kinetic studies. Journal of the Chinese Chemical Society, 65, 951-959, https://doi.org/10.1002/jccs.201700427.

[20] Santhi, T.; Manonmani, S.; Vasantha, V.S.; Chang, Y.T. (2016). A new alternative adsorbent for the removal of cationic dyes from aqueous solution. Arabian Journal of Chemistry, 9, S466-S474, https://doi.org/10.1016/j.arabjc.2011.06.004.

[21] Pathania, D.; Sharma, S.; Singh, P. (2013). Removal of methylene blue by adsorption onto activated carbon developed from Ficus carica bast. Arabian Journal of Chemistry, 10, S1445-S1451, https://doi.org/10.1016/j.arabjc.2013.04.021.

[22] Mustapha, S.; Shuaib, D.T.; Ndamitso, M.M.; Etsuyankpa, M.B.; Sumaila, A.; Mohammed, U.M.; Nasirudeen, M.B. (2019). Adsorption isotherm, kinetic and thermodynamic studies for the removal of $\mathrm{Pb}(\mathrm{II}), \mathrm{Cd}(\mathrm{II}), \mathrm{Zn}$ (II) and $\mathrm{Cu}$ (II) ions from aqueous solutions using Albizia lebbeck pods. Applied Water Science, 9, 142, https://doi.org/10.1007/s13201-019-1021-x.

[23] Teka, Tesfaye, and Semegn Enyew. 2014. Study on effect of different paramters on adsorption efficiency of low cost acitvated orange peels for the removal of methylene blue dye. Innovative Space of Scientific Research Journals 8:106-111.

(C) 2021 by the authors. This article is an open access article distributed under the terms and conditions of the Creative Commons Attribution (CC BY) license (http://creativecommons.org/licenses/by/4.0/). 